\title{
A study on major cardiovascular risk factors in Acute Coronary Syndrome (ACS) patient 40 years and below admitted in CCU of Shahid Gangalal National Heart Center.
}

\author{
Adhikari $\mathrm{CM}^{*}$,Rajbhandari $\mathrm{R}^{*}$,Limbu $\mathrm{YR}^{*}$,Malla $\mathrm{R}^{*}$,Sharma $\mathrm{R}^{*}$, Rauniyar $\mathrm{B}^{*}$, Rajbhandari \\ $S^{*}$, Baidya $S^{*}$,Sharma ${ }^{*}$, Maskey $A^{*}$, K.C MB* \\ *Department of Cardiology, SGNHC, Bansbari, Kathmandu
}

\section{ABSTRACT}

Coronary artery disease (CAD), predominately manifest in older individuals, is a devastating disease precisely because an otherwise healthy person in the prime of life may die or become disabled without warning. When the afflicted individual is under the age of 40 , the tragic consequences for family, friends, and occupation are particularly catastrophic and unexpected. Fortunately, the incidence of myocardial infarction (MI) and symptomatic CAD in young adults is low; most studies show that only about $3 \%$ of all CAD cases occur in this age range. Premature CAD is defined as cardiac events occurring before the age of 45 in men and 55 in women. In its severe form it is defined as CAD occurring below the age of 40 years. Prematurity and severity suggests that the disease starts at an early age and has a malignant course. In this study, we aim to investigate the major risk factor (smoking, Hypertension, Diabetes and dyslipidemia ) as defined by ACC-AHA pattern in ACS patient 40years or below admitted in Shahid Gangalal National Heart Centre (SGNHC) from April 2008 to April 2009. There were all together 54 ACS patients, male 44(81\%) and female $10(19 \%)$. HTN is the risk factor which was more commonly diagnosed and treated, while Dyslipidemia, DM and IFG were not usually diagnosed in young patient before they were diagnosed CAD. Dyslipidemia was the most common comprising $83.3 \%$ followed by HTN $70 \%$, smoking $70 \%$, abnormal blood glucose level $50 \%$, DM in $22.2 \%$ while IFG in $27.7 \%$. High total cholesterol (48\%) is the common form of dyslipidemia followed by high LDL (44.4\%), low HDL in $31.4 \%$. When non modifiable risk factor family history is excluded, $85 \%$ of the patients have two or more risk factors of CAD. When smoking along with family history is excluded $94.5 \%$ of the patients have 1 or more risks factors for CAD.

Keywords: acute coronary syndrome, risk factors

Correspondence:

Chandra Mani Adhikari

Shahid Gangalal National Heart Centre,

Bansbari,Kathmandu,Nepal

Tel: 00977-1-4371322, 00977-1-4371374.

Fax: 00977-1-4371123

Email:topjhap@hotmail.com 


\section{INTRODUCTION}

Coronary artery disease (CAD), predominately manifest in older individuals, is a devastating disease precisely because an otherwise healthy person in the prime of life may die or become disabled without warning. When the afflicted individual is under the age of 40 , the tragic consequences for family, friends, and occupation are particularly catastrophic and unexpected. Fortunately, the incidence of myocardial infarction (MI) and symptomatic CAD in young adults is low; most studies show that only about $3 \%$ of all CAD cases occur in this age range.$^{1,2}$

Many early studies ${ }^{3}$ evaluating these patients labeled them as having "premature" CAD. Premature CAD is defined as cardiac events occurring before the age of 45 in men and 55 in women. In its severe form it is defined as CAD occurring below the age of 40 years. Prematurity and severity suggests that the disease starts at an early age and has a malignant course. ${ }^{4}$ It is now better understood as a rapidly progressive form of the disease. ${ }^{5,6,7}$

A number of previous epidemiological studies have established the relationship between risk factors such as smoking, hypertension, dyslipidemia, and glucose intolerance and the occurrence of coronary artery disease (CAD) ${ }^{8,9} \mathrm{~A}$ recent report from the World Health Organization has also demonstrated that smoking, high blood pressure (HTN), and dyslipidemia are the most important risk factors for $\mathrm{CAD}^{10}$. Although there are few studies on risk factors in CAD patient but Till date there is no studies conducted regarding young CAD patients in Nepal. Thus in this study we aim to investigate the major risk factors in young ACS patients.

\section{OBJECTIVE}

The objective of this study was to investigate the major risk factor pattern in ACS patient 40 years or below.

\section{MATERIALS AND METHODS}

All ACS patients who are 40 years or below admitted in Cardiac Care Unit (CCU) of Shahid Gangalal National Heart Centre (SGNHC) from April
2008 to April 2009 were included in the Study. Patient who were diagnosed non- ST elevation Myocardial infarction (NSTEMI) or unstable angina (USA) need a significant stenosis in coronary angiogram (CAG) for inclusion.

\section{DATA COLLECTION}

All the data in this study were obtained from the hospital registry.

\section{Defining Cardiovascular Risk factors:}

Cardiovascular risk factors have been defined according to American College of Cardiology Key Data Elements and Definitions for Measuring the Clinical Management and Outcomes of Patients with ACS.

1. Family History of premature CAD: $C A D$ in male first degree relative $<55$ years; CAD in female first (degree relative <65years)

2. Smoking History confirming cigarette smoking

3. Dyslipidemia History of Dyslipidemia diagnosed and/or treated by physician. Or meets the criteria of National Cholesterol Education

Program criteria:

- Total cholesterol (TC)greater than $5.18 \mathrm{mmol} / \mathrm{l}$; or

- Low-density lipoprotein (LDL) greater than or equal to $3.37 \mathrm{mmol} / /$; or

- High-density lipoprotein (HDL) less than $1.04 \mathrm{mmol} / \mathrm{l}$.

4. Hypertension (HTN): Hypertension as documented by:

- History of hypertension diagnosed and treated with medication of life style modification.

- Blood pressure greater than $140 \mathrm{mmHg}$ systolic and /or90mmHg Diastolic on at least 2 occasions

5. Diabetes (DM): History of DM, need for antidiabetic agents of fasting glucose greater than $7 \mathrm{mmol} / \mathrm{l}$.

6. Impaired Fasting Glucose (IFG) Fasting blood glucose between $5.6-6.9 \mathrm{mmol} / \mathrm{l}$.

\section{RESULTS}

\section{Demographic features}

There were all together 54 ACS patients, male $44(81 \%)$ and female $10(19 \%)$.Mean age 37years, youngest of 29 years. There were 36 STEMI, 
A study on major cardiovascular risk factors in Acute Coronary Syndrome (ACS) patient 40 years and .........

5 NSTEMI and 13 Unstable Angina patients. (Table 1)

On the basis of prevalence of risk factors.

Table 1: Demographic features of patients

$\begin{array}{lcc} & \text { No. } & \text { Percentage }(\%) \\ \text { Male/Female } & 44 / 10 & 81 / 19 \\ \text { STEMI } & 36 & 66.6 \\ \text { NSTEMI } & 5 & 9.2 \\ \text { USA } & 13 & 24.2 \\ \text { Age } & 29-40 & \text { Mean } \\ & \text { years } & 37 \text { years }\end{array}$

2. Distribution of CAD risk factors before and after admission

Hypertension is the risk factor which was more commonly diagnosed and treated, while Dyslipidemia,DM and IFG were not usually diagnosed in young patient before they were diagnosed as having CAD.(Table 2)This shows that patient and physician were not aware in the diagnosis and management of risk factors.

$\begin{array}{lccc}\begin{array}{l}\text { Table 2: } \\ \text { before and After Admission } \\ \text { Risk Factor }\end{array} & \begin{array}{c}\text { Diagnosed } \\ \text { Before } \\ \text { Admission }\end{array} & \text { Treated } & \begin{array}{c}\text { Diagnosed } \\ \text { after } \\ \text { Admission }\end{array} \\ \text { HTN } & 17 & 6 & 13 \\ \text { DM/IFG } & 5 / 0 & 4 / 0 & 7 / 12 \\ \text { Dyslipidemia } & 3 & 0 & 42 \\ \text { Family History } & 7 & - & 7 \\ \text { Smoking } & 40 & - & 40\end{array}$

\section{Distribution of CAD risk factors}

On the basis of prevalence of risk factors Dyslipidemia was the most common comprising $83.3 \%$ followed by HTN $70 \%$, smoking $70 \%$, abnormal blood glucose level $50 \%$, DM in $22.2 \%$ while IFG in $27.7 \%$. ( Table 3)

Table 3: Distribution of CAD risk factors.

$\begin{array}{lcc}\text { Risk Factors } & \text { No. of Patients Percentage (\%) } \\ \text { Family History } & 7 & 12.9 \\ \text { Smoking } & 40 & 70.0 \\ \text { HTN } & 40 & 70.0 \\ \text { Dyslipidemia } & 45 & 83.3 \\ \text { Abnormal Glucose } & 27 & 50.0 \\ \text { DM } & 12 & 22.2 \\ \text { IFG } & 15 & 27.7\end{array}$

\section{Types of Dyslipidemia}

In patient of ACS age 40years or below High total cholesterol $(48 \%)$ is the common form of dyslipidemia followed by high LDL (44.4\%), low HDL in $31.4 \%$. Table 4

\begin{tabular}{|c|c|c|}
\hline & No. of Patients & Percentage (\%) \\
\hline \multicolumn{3}{|l|}{ High Total } \\
\hline Cholesterol & 26 & 48.0 \\
\hline High LDL & 24 & 44.4 \\
\hline LOW HDL & 17 & 31.4 \\
\hline
\end{tabular}

\section{Distribution of Risk factors burden}

When we exclude the non modifiable risk factor family history, $85 \%$ of the patients have two or more risk factors of CAD. (Table 5) When smoking along with family history is excluded $94.5 \%$ of the patients have 1 or more risks factors for CAD. Table 6

Table 5: Distribution of Risk factors burden

$\begin{array}{lcc}\text { Risk factors } & \text { No. of Patients } & \text { Percentage (\%) } \\ \text { None } & 1 & 1.8 \\ \text { One } & 7 & 12.9 \\ \text { Two } & 19 & 35.2 \\ \text { Three } & 15 & 27.8 \\ \text { Four } & 12 & 22.3\end{array}$

Table 6: Distribution of Risk factors burden (except smoking)

$\begin{array}{lcc}\text { Risk factors } & \text { No. of Patients } & \text { Percentage (\%) } \\ \text { None } & 3 & 5.6 \\ \text { One } & 19 & 35.2 \\ \text { Two } & 17 & 31.4 \\ \text { Three } & 15 & 27.8\end{array}$

\section{DISCUSSION}

This is the first study conducted in this group of patient in our centre. There are few important finding in this study which could be very useful in the management of the risk factors in the young population. It is a known fact that study of CAD and its risk factors in young individuals is important in the current era of preventive cardiology. ${ }^{11}$ Family history is a factor known to be present in many of these patients and probably represents a combination of risk factors that are genetically determined. ${ }^{12}$ But in our study family history of CAD was not that frequent. Most of the 
A study on major cardiovascular risk factors in Acute Coronary Syndrome (ACS) patient 40 years and .........

patients in our study are male which can easily be explained by the fact that male gender is prone to CAD. Cigarette smoking has been the single factor most strongly associated with CAD in the young adult 13,14 the relative risk for CAD was about three times higher in smokers age 35 to 44, compared to nonsmokers. Smoking was not only a prevalent risk factor, but its presence was an important predictor of long-term mortality regardless of treatment strategy. ${ }^{15}$ Studies reported that between $76 \%$ and $90 \%$ of young patients with $\mathrm{MI}$ are smokers compared with $40 \%$ of older patients with $\mathrm{MI}^{13,14}$ whereas our data suggest $70 \%$ of them were smoker. Though smoking is a well known risk factor for CAD still many young people are smoking which may just be because of ignorance or inability to educate the public about its risk in the development of CAD. Hypertension remains a standard risk factor associated with CAD. ${ }^{16}$ In our study HTN and smoking were present in $70 \%$ of the patient. As in our study abnormal blood glucose and hyperlipidemia are frequently present in young CAD patients in other studies. The importance of these factors in the pathogenesis of CAD and their powerful relationship to rapid disease progression is well documented 17,18 . Diabetes is found in only about $15 \%$ to $20 \%$ of all young CAD patients which is comparable to our data. ${ }^{19}$ Our study clearly demonstrate that Dyslipidemia, HTN and smoking were the most common risk factors in these patients which clearly suggest that diagnosis and treatment of these risk factors are the most important in the primary prevention of CAD in young population.

The most interesting fact we found in our study is most of the risk factors were not diagnosed and treated before they are diagnosed to have ACS. Though dyslipidemia is the most common risk factor but none of the patients were treated; it may just be because of the less attention given to this risk factor. The interesting finding was most of these patients have more than two risk factors. which suggest that the risk factor in these patient occurs in clusters.

Numerous studies 19,20 have demonstrated the surprisingly good prognosis up to three years after diagnosis of CAD in the young adult. But there is a huge impact in the mobidity and expenses in the therapy so there There is a need for identifying and correcting the conventional risk factors like hypertension, diabetes mellitus, smoking, hyperlipidaemia, tobacco consumption, and central obesity at much younger age.

\section{CONCLUSION}

Dyslipidemia, HTN and smoking were the most common risk factors in these patients. These risk factors occur in group in the young ACS patient. These risk factors are not diagnosed and treated before the patient are diagnosed as ACS.As management of risk factor is important aspect in the primary prevention of CAD, everyone should be aware about these risk factors and their diagnosis and treatment. But the important question still remains unanswered at what age we should start to screen and treat these risk factors as people at the age of twenty and thirty are presenting with the ACS.

\section{NHJ | VOLUME 7 | NO. 1 | NOVEMBER, 2010 (special issue)}




\section{REFERENCES}

1. Jalowiel DA, Hill JA. Myocardial infarction in the young and in women. Cardiovasc Clin 1989;20:197-206.

2. Navas-Nacher EL, Colangelo L, Beam C, Greenland P. Risk factors for coronary heart disease in men 18 to 39 years of age. Ann Intern, Med 2001;134:433-9.

3. Yater WM, Traum AH, Brown WL, Fitzgerald RP, Geisler MA, Wilcox B. Coronary artery disease in men eighteen to thirty-nine years of age. Am Heart J 1948;36:334-48.

4. HS Rissam*, S Kishore*, N Trehan*Coronary Artery Disease in Young Indians -The Missing Link Journal, Indian Academy of Clinical Medicine Vol. 2, No. 3

5. Sturzenhofecker P, Samek L, Droste C, Gohlke H, Petersen J, Roskamm H. Prognosis of coronary heart disease and progression of coronary atherosclerosis postinfarction in patients under the age of 40. In: Roskamm $\mathrm{H}$, editor. Myocardial Infarction at Young Age. New York, NY: Springer-Verlag, 1982:82-91.

6. Fournier JA, Sanchez A, Quero J, et al. Myocardial infarction in men aged 40 years or less: a prospective clinical angiographic study. Clin Cardiol 1996;19:631-6.

7. Chen L, Chester M, Kaski JC. Clinical factors and angiographic patterns associated with premature coronary artery disease. Chest 1995;108:364 -9.

8. Castelli WP.Epidemiology of coronary heart disease:The Fram- ingham Study.Am J Med $76: 4-12,1984$.

9. Hubert HB,Feinleib M,Mc Namara PM,Castelli WP.Obesity as an independent risk factor for cardiovascular disease:A 26-year followup of participants in the Framingham Heart Study.Circula-tion $67: 968-977,1983$.

10. WHO:Reducing risks, promoting healthy life. The World Health Report 2002.

11. Jason H. Cole, Joseph I. Miller, III, Laurence S. Sperling, and William S. Weintraub Longterm follow-up of coronary artery disease presenting in young adults japan, J. Am. Coll. Cardiol,2003;41;521-528.
12. Yater WM, Traum AH, Brown WL, Fitzgerald RP, Geisler MA, Wilcox B. Coronary artery disease in men eighteen to thirty-nine years of age. Am Heart J 1948;36:334 -48.

13. Chen L, Chester M, Kaski JC. Clinical factors and angiographic features associated with premature coronary artery disease. Chest 1995;108:364 -9.

14. Zimmerman FH, Cameron A, Fisher LD, Ng G. Myocardial infarction in young adults: angiographic characterization, risk factors and prognosis. (Coronary Artery Surgery Registry.) J Am Coll Cardiol 1995;26:654 -61.

15. Kannel W, McGee D, Castelli W. Latest perspectives on cigarette smoking and cardiovascular disease: the Framingham Study. J Card Rehabil 1984;4:267-77. HS Rissam*, S Kishore*, N Trehan ${ }^{*}$ Coronary Artery Disease in Young Indians -The Missing Link Journal, Indian Academy of Clinical Medicine Vol. 2, No.

16. Krolewski AS, Kosinski EJ, Warram JH, et al. Magnitude and determinants of coronary artery disease in juvenile onset, insulin dependent diabetes mellitus. Am J Cardiol 1987;59:750 -5.

17. H Klag MJ, Ford DE, Mead LA, et al. Serum cholesterol in young men and subsequent cardiovascular disease. $\mathrm{N}$ Engl J Med 1993;328:313-8.

18. Nevas-Nacher EL, Colangelo L, Beam C, Greenland P. Risk factors for coronary heart disease in men age 18 to 39 years of age. Ann Intern Med 2001;134:433-9.

19. Sturzenhofecker P, Samek L, Droste C, Gohke H, Petersen J, Roskamm H. Prognosis of coronary heart disease and progression of coronary atherosclerosis postinfarction in patients under the age of 40. In: Roskamm $\mathrm{H}$, editor. Myocardial Infarction at Young Age. New York, NY: Springer-Verlag, 1982:82-91.

20. Fournier JA, Sanchez A, Quero J, et al. Myocardial infarction in men aged 40 years or less: a prospective clinical angiographic study. Clin Cardiol 1996;19:631-6. 